\title{
EDITORIAL
}

\section{The agency of students, teachers and learning technologists}

The articles in this issue reveal the commitment of $A L T-J$ to publish research that addresses the perspectives of a range of stakeholders in learning technology: in this case, students, teachers and learning technologists themselves. Although the articles are wide-ranging in their scope and approaches, we can detect some important and common themes. The first of these is agency: learning technology research can fall into the trap of focusing on the technology that is offered rather than what people do with or without it. The second is online discussion: although computer conferencing has been used in education since the 1980s, student engagement remains a thorny issue for practice, and one that demands additional research. Thirdly, the role of learning technologists remains in question: how can they support staff and students through their practice and research?

Czerniewicz, Williams and Brown's article has been developed from the ALT-C 2008 prize-winning paper on student agency: a study of their access (social, technical, practical and contextual) to Information and Communication Technologies (ICTs) in three different universities in South Africa. Archer's agency theory is used to explore from the student perspective the relation between agency and structure. Their findings indicate the reflexivity of students' responses to constraints they may encounter: for example, the use of cell phones by students in low socio-economic groups.

The second article by Skinner uses a theory from beyond the discipline of learning technology, namely community engagement theory, to investigate participation in online discussion in a level one undergraduate module. She concludes that engagement of all students from the start is necessary to build a strong sense of community.

Online discussion is also the focus of the next article, where Enriquez critiques existing research frameworks for online discussion that rely on content analysis. She proposes the inclusion of genre analysis as a means of capturing the situated and emergent nature of online discussion as a communicative practice. These ideas are relevant to practitioners and researchers in learning technology.

Peacock et al. explore the changing roles of learning technologists, not only as researchers or practitioners in learning technology, but also as members of multidisciplinary research teams. The study explores whether such interventions can help to address any polarisation between practitioner and research roles for learning technologists.

The bridge between research and practice is also a theme in the next article by Schoonenboom, Sligte and Kliphuis. They report on the derivation and testing of guidelines for supporting re-use of digital learning materials: both from the literature and from practice case studies. Their study not only validates the guidelines but also makes them more usable by readers.

Finally, Middleton's fascinating study of a podcasting pilot in higher education captures rich responses of staff and students. The findings capture the real possibilities 
of using audio and the contrast between reality and expectations; for example, audio is used to 'soften' the VLE, rather than to feed audio (using the RSS standard) directly to students.

The work reported in this issue indicates the growing confidence of learning technology researchers, a willingness to reach beyond traditional boundaries. We can see this both in the grounded, people-centred approaches adopted, and in the inclusion of theories and methods from elsewhere: Archer's agency theory, community engagement theory and genre analysis. Technology can offer new opportunities for learning, but only if practitioners, students and teachers can engage with it and understand its use in context. Research in learning technology can contribute to this understanding.

Frances Bell University of Salford, UK 